\title{
Synthesis of magnetic core-branched Au shell nanostructures and their application in cancer-related miRNA detection via SERS
}

\author{
Yanjun Yang ${ }^{\dagger}$, Xinyu Jiang ${ }^{\dagger}$, Jie Chao, Chunyuan Song ${ }^{*}$, Bing Liu, Dan Zhu, Youzhi Sun, Boyue Yang, \\ Qiaowei Zhang, Ye Chen and Lianhui Wang*
}

\begin{abstract}
Magnetic core gold shell nanostructures which integrate both SERS activity and superparamagnetism are widely utilized in SERS-based detection as SERS substrates, sample separation and preconcentration operators, as well as external magnetic field controlled directional carrier. However, most of the reported gold shells coated on the magnetic cores had smooth surfaces rather than branched nanostructures with enhanced SERS activity. Here, a novel type of $\mathrm{Fe}_{3} \mathrm{O}_{4}$-Au core-shell nanoparticles with branched gold shell was prepared by a seed-mediated method together with the shape induction agent $\mathrm{AgNO}_{3}$, and their growth process and mechanism, properties, as well as morphologically controlled synthesis were also investigated. The branched gold coated magnetic nanoparticles (B-GMNPs) with improved SERS performance were further utilized to build superparamagnetic and SERS-active capturers by assembling tetrahedral DNA onto their surfaces for sandwich-structured detection of cancer-related biomarker miRNA- 21 . The experimental results indicate that highly sensitive and specific detections can be obtained by the proposed SERS sensing system including B-GMNPs and tetrahedral DNA, and the limit of detection (LOD) of miRNA-21 in serum is $623 \mathrm{amol} \mathrm{L}^{-1}$. These B-GMNPs can be used as good SERS substrates with the functions of external magnetic field controlled sample separation and directional enrichment for effective SERS-based biochemical sensing and detections.
\end{abstract}

Keywords: magnetic nanoparticles, branched Au shell, DNA tetrahedron, SERS, miRNA

\section{INTRODUCTION}

Iron oxides as the most commonly used magnetic nanoparticles (MNPs) have attracted great interest of nanomate- rial scientists from a wide range of research fields, including micro/nanoelectronics, catalysis, chemical sensing, information storage, and medical diagnostics [1-4]. Generally, surface modifications of MNPs are very important to improve their physical and chemical stability, as well as making them possess more amazing functions especially for biological application, including magnetic resonance imaging, controlled drug delivery, photothermal therapy, bio-separation and biological assays [5-7]. One of the most promising modifications is coating a gold shell since gold has good stability, biocompatibility, and so called "surface plasmon resonance" property. The unique combination of the nanoscale magnetic core and the plasmonic Au shell has opened new avenues in bio-sensing, where two different physical properties of same nanoparticles can be harnessed for detection. Among them one of the most representatives is surface-enhanced Raman scattering (SERS) based assay $[8,9]$, which is known as a powerful tool for ultrasensitive trace detection [10-15].

Up to now, there have been a number of examples reporting on the synthesis of gold coated MNPs (MNPs@Au). Generally, gold shell can be formed directly or indirectly on the magnetic core [16-18]. In the indirect methods, an intermediate adhesive layer, such as poly-L-histidine [19], cross-linked polymer poly(cyclotriphosphazene-co-4,4'-sulfonyldiphenol) [20], polyethyleneimine [21], and silica [22], is sandwiched between the core and Au shell. Recently, most published studies have made great efforts to solve the two big challenges, i.e., gold coating is to ensure that the nanoparticles are fully coated and

Key Lab for Organic Electronics \& Information Displays (KLOEID), Institute of Advanced Materials (IAM), Jiangsu National Synergetic Innovation Center for Advanced Materials (SICAM), Nanjing University of Posts \& Telecommunications, Nanjing 210023, China

${ }^{\dagger}$ These authors contributed equally to this work.

* Corresponding authors (emails: iamcysong@njupt.edu.cn (Song C); iamlhwang@njupt.edu.cn (Wang L)) 
do not expose iron or iron oxide, and to precisely control the shell thickness and obtain a smooth gold surface [23]. However, few studies have been conducted specifically on the preparation of highly SERS-active gold shell on the magnetic nanoparticles [24-28], and mainly partially gold coated rough shell or fully coated smooth shell have been prepared for SERS-based detections, which limits the application of MNPs@Au in the field of SERS. According to the SERS mechanism rough surface with nanoscale gaps or tips can generate stronger localized surface plasmon resonance (LSPR) compared with the smooth ones [29-31]. Though many gold nanoparticles with branched tips, such as tadpole- [32], star- [33], and urchin-shaped [34], were synthesized with enhanced SERS activities, few researches have been carried on the growth of branched gold shell on the magnetic cores with improved SERS performance.

In the present work, a novel type of branched gold coated magnetic nanoparticles (B-GMNPs) has been prepared by a seed-mediated synthesis method. The magnetic nanoparticle $\left(\mathrm{Fe}_{3} \mathrm{O}_{4}\right)$ was coated with a silica shell $\left(\mathrm{Fe}_{3} \mathrm{O}_{4} @ \mathrm{SiO}_{2}\right)$ first, and then gold seeds were adsorbed onto the $\mathrm{SiO}_{2}$ shell ( $\mathrm{Fe}_{3} \mathrm{O}_{4} @ \mathrm{SiO}_{2} @ \mathrm{Au}$ seeds), finally branched $\mathrm{Au}$ shell was synthesized in the growth solution by adding a shape induction agent $\mathrm{AgNO}_{3}$ for directional growth of branches. The growth process and mechanism, properties, as well as morphologically controlled synthesis of the magnetic core-branched gold shell nanostructures were investigated. The proposed B-GMNPs with improved SERS activities were further utilized as SERS-active magnetic capturer to assay cancer-related biomarker miRNA-21 in serum by a sandwich-structured strategy. In view of the remarkable advantages of DNA tetrahedrons, including good mechanical rigidity and structural stability, well controlled density and orientation of DNA capturers, enhanced accessibility of targets, as well as minimized nonspecific adsorption on the surface [35-41], tetrahedral DNAs containing the complementary sequence of target were structured first and then assembled onto the B-GMNPs to build SERS-active capturers with magnetic response. By using the tetrahedral DNA modified B-GMNPs as SERS-active capturers, sample separation and preconcentration operators, highly sensitive and specific detections of cancer-related biomarker miRNA-21 were conducted.

\section{EXPERIMENTAL SECTION}

\section{Materials}

Gold(III) chloride trihydrate $\left(\mathrm{HAuCl}_{4} \cdot 3 \mathrm{H}_{2} \mathrm{O}, \quad 49.87 \%\right.$

$\mathrm{Au}$, iron(III) chloride hexahydrate (97\%), and
iron(II) chloride tetrahydrate (98\%) were purchased from Alfa Aesar. 4-Mercaptobenzoic acid (4-MBA), 5,5'-dithiobis-(2-nitrobenzoic acid) (DTNB, 99\%), tetrakis(hydroxymethyl)phosphonium chloride (THPC, $80 \%$ aqueous solution) were obtained from Sigma-Aldrich. Silver nitrate $\left(\mathrm{AgNO}_{3}, 99.8 \%\right)$, sodium hydroxide $(\mathrm{NaOH}$, $\geq 96 \%)$, potassium carbonate $\left(\mathrm{K}_{2} \mathrm{CO}_{3}, \geq 99 \%\right)$, and ethanol ( $\geq 99.7 \%$ ) were bought from Sinopharm Chemical Reagent Co., Ltd. 3-Aminopropyltriethoxysilane (APTES, 98\%), tetraethyl orthosilicate (TEOS), ammonia solution $(\geq 25 \%)$, and formaldehyde solution (37\%-40\%) were purchased from Aladdin. Gold nanoparticles $(15 \mathrm{~nm})$ were obtained from British Biocell International (Cardiff, UK). The DNA and miRNA oligonucleotides listed in Table S1 (Supplementary information) were synthesized and HPLC-purified by Takara Biotechnology (Dalian, China), in which thiol-modified single stranded DNAs (ssDNAs) sequences A, B, C, and a special designed oligonucleotide D containing a complementary sequence to the target were used to structure DNA tetrahedrons, the probe DNA with complementary sequence to the target was utilized to fabricate SERS tags, miRNA-21 was the target, single-base mismatch (SM) denoted the oligonucleotide with a single-base mismatch with miRNA-21, and miRNA-486/375 were selected as noncomplementary miRNAs. Unless otherwise specified, all the materials were used without additional purification, and sterilized ultrapure Millipore water $(18.2 \mathrm{M} \Omega \mathrm{cm}$ ) was used as the solvent throughout. Different buffers, TBE buffer $\left(89 \mathrm{mmolL}^{-1}\right.$ Tris, $90 \mathrm{mmolL}^{-1}$ boric acid, $2 \mathrm{mmolL}^{-1}$ ethylenediaminetetraacetic acid (EDTA), $\mathrm{pH}$ 8.0), TM buffer $\left(20 \mathrm{mmolL}^{-1}\right.$ Tris, $50 \mathrm{mmolL}^{-1} \mathrm{MgCl}_{2}$, $\mathrm{pH} \quad 8.0)$, TBE- $\mathrm{Mg}^{2+}$ buffer $\left(89 \mathrm{mmolL}^{-1}\right.$ Tris, $90 \mathrm{mmolL}^{-1}$ boric acid, $2 \mathrm{mmol} \mathrm{L}^{-1}$ EDTA, $\left.12.5 \mathrm{mmolL}^{-1} \quad \mathrm{MgCl}_{2}\right)$, $\mathrm{PBS} 1\left(10 \mathrm{mmolL}^{-1} \quad \mathrm{NaH}_{2} \mathrm{PO}_{4} / 10\right.$ $\mathrm{mmolL}^{-1} \mathrm{Na}_{2} \mathrm{HPO}_{4}, 50 \mathrm{mmolL}^{-1} \mathrm{NaCl}, \mathrm{pH}$ 7.4), and PBS2 (10 mmolL $\mathrm{m}^{-1} \quad \mathrm{NaH}_{2} \mathrm{PO}_{4} / 10 \quad \mathrm{mmolL}^{-1} \quad \mathrm{Na}_{2} \mathrm{HPO}_{4}$, $100 \mathrm{mmolL}^{-1} \mathrm{NaCl}, \mathrm{pH} 7.4$ ), were prepared and used for the treatment of nucleic acids.

\section{Synthesis of branched gold coated magnetic nanoparticles (B-GMNPs)}

The magnetic core-branched $\mathrm{Au}$ shell nanostructures were synthesized by four steps, i.e., synthesizing magnetic nanoparticles $\left(\mathrm{Fe}_{3} \mathrm{O}_{4}\right)$, coating $\mathrm{Fe}_{3} \mathrm{O}_{4}$ nanoparticles with silica shell $\left(\mathrm{Fe}_{3} \mathrm{O}_{4} @ \mathrm{SiO}_{2}\right)$, adsorbing gold seeds onto the $\mathrm{SiO}_{2}$ shells $\left(\mathrm{Fe}_{3} \mathrm{O}_{4} @ \mathrm{SiO}_{2} @ \mathrm{Au}\right.$ seeds), and finally growing branched Au shells to obtain branched $\mathrm{Fe}_{3} \mathrm{O}_{4} @ \mathrm{SiO}_{2} @ \mathrm{Au}$ nanoparticles (B-GMNPs). The first three steps were 
carried out following our previous reports [22,42], and the morphology and absorption characterizations of $\mathrm{Fe}_{3} \mathrm{O}_{4}, \mathrm{Fe}_{3} \mathrm{O}_{4} @ \mathrm{SiO}_{2}$, and $\mathrm{Fe}_{3} \mathrm{O}_{4} @ \mathrm{SiO}_{2} @ \mathrm{Au}$ seeds, as well as the hysteresis loop of $\mathrm{Fe}_{3} \mathrm{O}_{4}$ are shown in Fig. S1. In the last step, the branched $\mathrm{Au}$ shells were synthesized by the seed-mediated synthesis. Firstly, $720 \mu \mathrm{L}$ of $0.1 \mathrm{molL}^{-1} \mathrm{~K}_{2} \mathrm{CO}_{3}$ and $760 \mu \mathrm{L}$ of $20 \mathrm{mmol} \mathrm{L}^{-1} \mathrm{HAuCl}_{4}$ were added together into $20 \mathrm{~mL}$ water under vigorous stirring for $20 \mathrm{~min}$ to obtain the $\mathrm{Au}$ shell growth solution. Secondly, $20 \mu \mathrm{L}$ of $10 \mathrm{mmol} \mathrm{L}^{-1} \mathrm{AgNO}_{3}$ was added into $100 \mu \mathrm{L}$ of $\mathrm{Fe}_{3} \mathrm{O}_{4} @ \mathrm{SiO}_{2} @ \mathrm{Au}$ seeds under sonication for $10 \mathrm{~min}$, and then the mixture was poured into the growth solution. After vigorous stirring for $2 \mathrm{~min}, 100 \mu \mathrm{L}$ formaldehyde solution was dropped into the solution under continuous stirring for $2 \mathrm{~min}$. Thirdly, the mixture was maintained undisturbedly for $30 \mathrm{~min}$ at $28^{\circ} \mathrm{C}$. Finally, the as-synthesized colloid was centrifuged at $2500 \mathrm{rpm}$ for $15 \mathrm{~min}$ to remove the excess reactants. The precipitates were washed three times and finally re-dispersed to $3 \mathrm{~mL}$ with water. As control, the $\mathrm{Fe}_{3} \mathrm{O}_{4} @ \mathrm{SiO}_{2} @ \mathrm{Au}$ nanoparticles with smooth Au shells (denoted as S-GMNPs) were also synthesized by the same strategy but without adding $\mathrm{AgNO}_{3}$. The sketch maps of the B-GMNPs and S-GMNPs preparations are shown in Scheme 1a.

\section{Preparation of SERS tags}

The SERS tags were prepared by labeling probe DNA and Raman reporter DTNB onto the AuNPs in sequence, which can be seen from the magnified image shown in Scheme 1c. Specifically, $500 \mu \mathrm{L}$ of $15 \mathrm{~nm}$ colloidal AuNPs $\left(2.3 \mathrm{nmolL}^{-1}\right)$ was mixed with $50 \mu \mathrm{L}$ of $10 \mu \mathrm{molL}^{-1}$ probe DNA in $0.5 \times$ $\mathrm{TBE}$ and incubated at $25^{\circ} \mathrm{C}$ for more than $4 \mathrm{~h}$. Then 12.5 $\mu \mathrm{L}$ of $2 \mathrm{molL}^{-1} \mathrm{NaCl}$ solution was added slowly into the mixture for four times in $2 \mathrm{~h}$ with the final concentration of $\mathrm{NaCl}$ reaching $200 \mathrm{mmol} \mathrm{L}^{-1}$. The mixture aged at $25^{\circ} \mathrm{C}$ overnight. The probe DNA functionalized AuNPs were washed by $0.5 \times$ TBE buffer by centrifugation $(8500 \mathrm{rpm}$, $20 \mathrm{~min}$ ) for three times and finally re-dispersed to $500 \mu \mathrm{L}$. Next, $5 \mu \mathrm{L}$ of $100 \mu \mathrm{mol} \mathrm{L}{ }^{-1}$ DTNB (in ethanol) was added into the probe DNA functionalized AuNPs to label DTNB molecules onto the AuNPs. After stirring for $3 \mathrm{~h}$, three times centrifugal purifications were repeated and the final

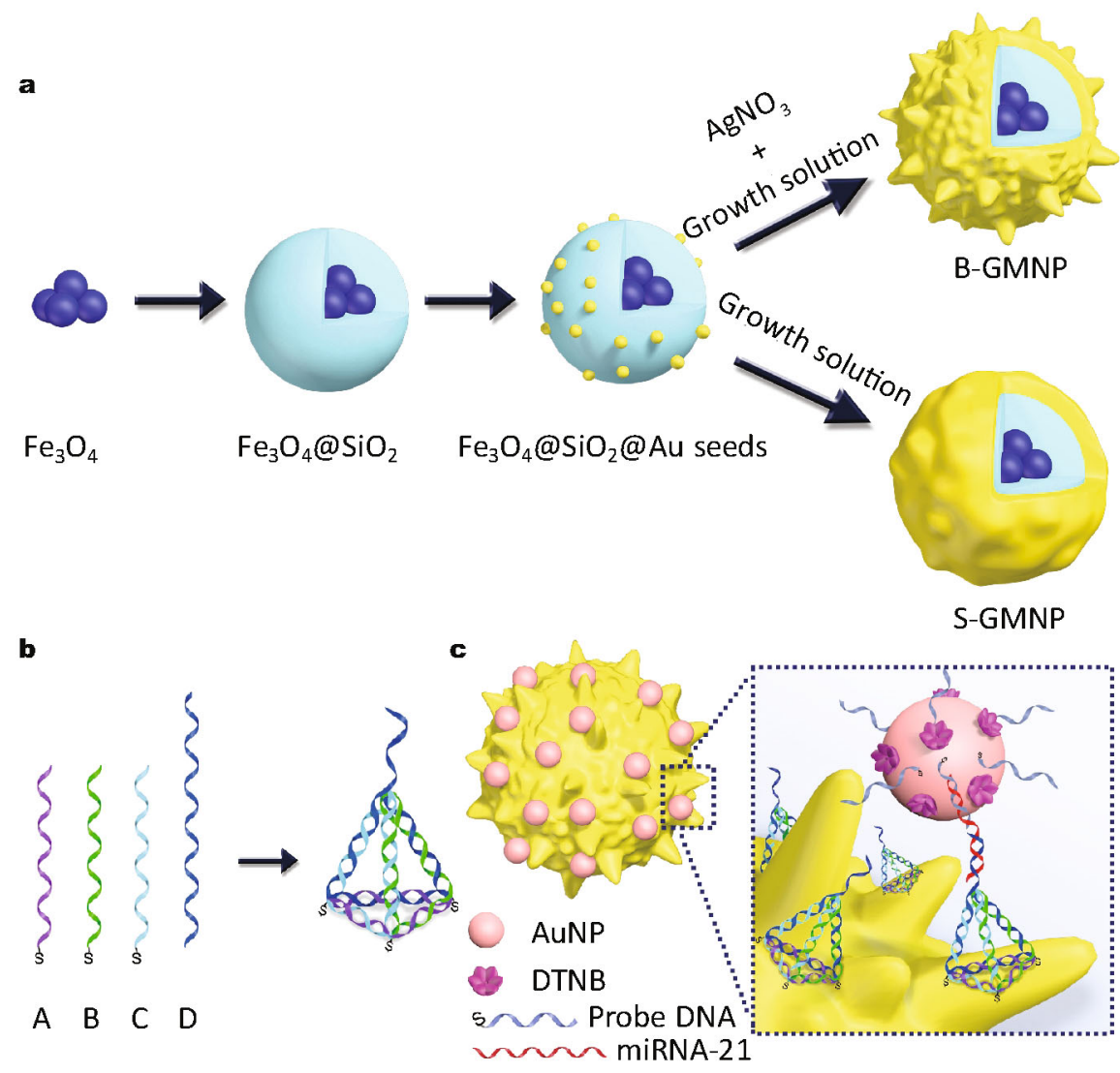

Scheme 1 (a) Sketch maps of the preparation of B-GMNPs and S-GMNPs; (b) construction of tetrahedral DNA; (c) sandwich-structured strategy by using tetrahedral DNA modified B-GMNPs and SERS tags to assay cancer-related biomarker miRNA-21. 
probe DNA and DTNB labeled AuNPs, i.e., SERS tags, were obtained by re-dispersing the precipitates with $50 \mu \mathrm{L}$ PBS2.

\section{Preparation of DNA tetrahedrons}

Scheme $1 \mathrm{~b}$ illustrates the construction of DNA tetrahedrons. Equimolar quantities of four single stranded DNA sequences ( $\mathrm{A}, \mathrm{B}, \mathrm{C}$ and $\mathrm{D}$ listed in Table S1) were mixed in $\mathrm{TM}$ buffer at $95^{\circ} \mathrm{C}$ for $5 \mathrm{~min}$ and then cooled to $4^{\circ} \mathrm{C}$ to structure DNA tetrahedrons with the final concentration of $1 \mu \mathrm{molL} \mathrm{L}^{-1}$. The four ssDNAs can assemble into tetrahedral DNA by the hybridization of complementary partial sequences marked in the same colors in Table S1, and leave the red marked single stranded sequence free to specifically capture target. In order to verify the assembly of DNA tetrahedron, native polyacrylamide gel electrophoresis (native-PAGE) was performed. DNA tetrahedrons were run on $10 \%$ native-PAGE gel in $1 \times \mathrm{TBE}-\mathrm{Mg}^{2+}$ buffer with a stable voltage of $80 \mathrm{~V}$ in ice bath for $130 \mathrm{~min}$.

\section{Preparation of B-GMNPs@DNA tetrahedrons}

DNA tetrahedrons were diluted by PBS1 to a final concentration of $0.1 \mu \mathrm{molL}^{-1}$ for preparing superparamagnetic and SERS-active detection substrates (B-GMNPs@DNA tetrahedrons) by assembling DNA tetrahedrons onto the B-GMNPs via S-metal bonds. Briefly, $500 \mu \mathrm{L}$ colloidal B-GMNPs were incubated with $20 \mu \mathrm{L}$ of $0.1 \mu \mathrm{molL}^{-1}$ DNA tetrahedron in PBS1 overnight. The products were purified by centrifuging three times at $2500 \mathrm{rpm}$ for $15 \mathrm{~min}$. The precipitates were collected and re-dispersed into $500 \mu \mathrm{L}$ PBS1.

\section{Sensing protocol}

Scheme 1c shows the sandwich-structured sensing protocol. For detecting target miRNA-21, $50 \mu \mathrm{L}$ SERS tags and $50 \mu \mathrm{L}$ B-GMNPs@DNA tetrahedrons were added together into a sterile tube followed by fully shaking. Subsequently, $10 \mu \mathrm{L}$ target miRNA-21 with a certain concentration (diluted in PBS2) was added into the mixture and incubated at $37^{\circ} \mathrm{C}$ for $3 \mathrm{~h}$ under shaking. After that, the sandwich-structured composites were collected from the solution by magnet separation and washed three times by PBS2. Finally, the purified composites were dispersed in $30 \mu \mathrm{L}$ PBS2 for further SERS measurements.

\section{SERS measurements}

The as-synthesized different GMNPs were concentrated and quantified to the same gold content of $168.75 \mathrm{mgL}^{-1}$ by inductively coupled plasma mass spectrometry (ICP-MS). Then $200 \mu \mathrm{L}$ of the as-synthesized GMNPs was mixed with $30 \mu \mathrm{L}$ of $100 \mu \mathrm{mol} \mathrm{L}{ }^{-1}$ Raman reporter 4-MBA followed by ultrasonically dispersing and incubating for $12 \mathrm{~h}$. For each SERS characterization, three aliquots of $20 \mu \mathrm{L}$ final colloidal samples were dropped into three micropores (diameter $3 \mathrm{~mm}$ ) on a silicon wafer. The samples were kept wet during SERS measurements. SERS measurements were performed using $177.2 \mathrm{~mW}$ laser power, $10 \mathrm{~s}$ acquisition time. For miRNA-21 detections, three aliquots of $10 \mu \mathrm{L}$ final composites after hybridizations and further magnetically purifications were dropped onto three silicon wafers $(0.5 \mathrm{~cm} \times 0.5 \mathrm{~cm})$ respectively. Under each droplet there was placed a cylindrical magnet (diameter $\sim 1.5 \mathrm{~mm}$, length $\sim 10 \mathrm{~mm}$ ) to magnetically concentrate the composites into a small spot with diameter less than $2 \mathrm{~mm}$. SERS scans ( $9 \mathrm{~mW}$ laser power, $2 \mathrm{~s}$ acquisition time) were performed in the spot. For each sample, ten times SERS scans were repeated at different positions to obtain an averaged SERS spectrum and the baselines were removed by the software Wire 4.0.

\section{Instruments}

Absorption spectra were collected using a UV-vis-NIR spectrophotometer (UV-3600, Shimadzu, Japan). Scanning electron microscopy (SEM) images were recorded by a field emission scanning electron microscopy (S-4800, Hitachi, Japan) operating at $5 \mathrm{kV}$. Transmission electron microscopy (TEM) (HT7700, Hitachi, Japan) was utilized to take TEM images, while high-resolution transmission electron micrographs (HRTEM) were taken by an FEI Tecnai G2 TEM. TEM images of the as-prepared nanoparticles were used for size distribution measurements. For each sample the dimensions of particles were quantified using Nano measurer software. X-ray diffraction (XRD) analysis was carried out using an X-ray diffractometer (D8 Advance, Bruker, Germany). Vibrating sample magnetometer (VSM) (VSM 7400, Lake Shore, USA) was used to measure room temperature magnetic properties and obtain hysteresis loops. Zeta potential measurements were conducted by Zeta potential analyzer (ZetaPALS, Brookhaven, America). The SERS spectra were recorded by a confocal Raman microscope (InVia, Renishaw, England) using $785 \mathrm{~nm}$ excitation laser beam and $20 \times$ objective lens.

\section{RESULTS AND DISCUSSION}

\section{Characterizations of B-GMNPs}

The synthesis of branched shell was tried according to our previous work for synthesizing S-GMNPs [22,42], i.e., the $\mathrm{Fe}_{3} \mathrm{O}_{4} @ \mathrm{SiO}_{2} @ \mathrm{Au}$ nanoparticles with smooth Au shells were synthesized by using the growth solution containing 
$380 \mu \mathrm{L} \mathrm{HAuCl}_{4}$ solution $\left(20 \mathrm{mmol} \mathrm{L}^{-1}\right)$ and $360 \mu \mathrm{L} \mathrm{K}_{2} \mathrm{CO}_{3}$ solution $\left(0.1 \mathrm{~mol} \mathrm{~L}^{-1}\right)$ (designated as one fold $\left.(\times 1)\right)$ in the absence of $\mathrm{AgNO}_{3}$. As overall views shown in Fig. 1a (SEM) and $d$ (TEM), the S-GMNPs have smooth gold shells exhibiting spherical or ellipsoidal contours and their average diameter is $170 \pm 12 \mathrm{~nm}$, which grows bigger relative to the $\mathrm{Fe}_{3} \mathrm{O}_{4} @ \mathrm{SiO}_{2} @ \mathrm{Au}$ seeds $(126 \pm 15 \mathrm{~nm})$ shown in Fig. S1c. The LSPR peak of the S-GMNPs is centered at $648 \mathrm{~nm}$ (black curve, Fig. $1 \mathrm{~g})$. When two folds $(\times 2)$ of the growth solution was added, the smooth Au shells grow thicker and the averaged overall size of the nanoparticles grows bigger to $180 \pm 13 \mathrm{~nm}$ (Fig. 1b, e), as a result the LSPR peak red-shifts to $676 \mathrm{~nm}$ (red curve in Fig. 1g). Significant changes of surface morphology of GMNPs are obtained by introducing $20 \mu \mathrm{L}$ of $10 \mathrm{mmolL}^{-1} \mathrm{AgNO}_{3}$ into the reaction system. As shown in Fig. 1c, f, rough Au shells can be observed distinctly on the GMNPs and their surfaces are occupied by many dense and branch-like protrusions, which can be designated as branched gold-coated magnetic nanoparticles (B-GMNPs). The B-GMNPs possess spherical contours with an average diameter of $210 \pm 15 \mathrm{~nm}$, and some branches have an appropriate length of $20 \pm 2 \mathrm{~nm}$. The morphology changes lead to a large red-shift of LSPR peak to $770 \mathrm{~nm}$ (green curve in Fig. 1g). The experimental results indicate that the branched $\mathrm{Au}$ shell can be obtained by using the shape induction agent $\mathrm{AgNO}_{3}$, while smooth gold shells are prepared without $\mathrm{AgNO}_{3}$ despite feeding more gold precursor $\mathrm{HAuCl}_{4}$. Fig. $1 \mathrm{~h}$ shows the averaged SERS spectra of 4-MBA obtained on the three types of nanostructures showing in Fig. 1a-c. The two charac-
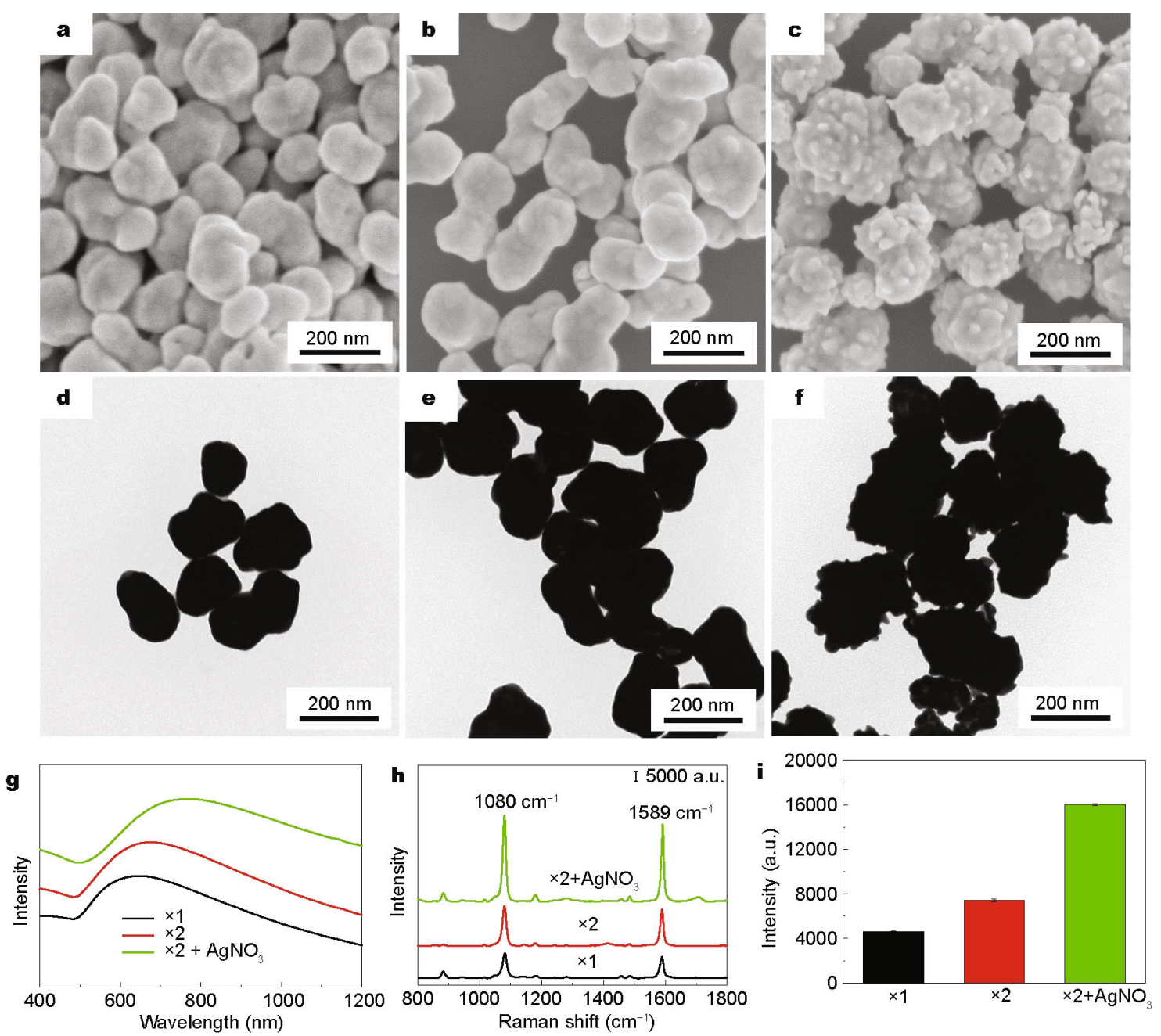

Figure 1 Characterizations of the S-GMNPs and B-GMNPs. (a-c) SEM images of the nanoparticles synthesized by $\times 1$ Au shell growth solution, $\times 2$ $\mathrm{Au}$ shell growth solution, and $\times 2 \mathrm{Au}$ shell growth solution with $10 \mu \mathrm{L} \mathrm{AgNO}_{3}$, respectively; (d-f) corresponding TEM images of the three nanoparticles showing in (a-c); (g) absorption spectra; (h) averaged SERS spectra of 4-MBA obtained from the three nanoparticles; (i) SERS intensities of 4-MBA at $1080 \mathrm{~cm}^{-1}$ corresponding to the three nanoparticles respectively $(n=10)$. 
teristic peaks of 4-MBA at 1080 and $1589 \mathrm{~cm}^{-1}$ which are assigned to $v_{8 \mathrm{a}}$ and $v_{12}$ aromatic ring vibrations can be clearly observed from the three spectra [43]. By characterizing the SERS intensity of $4-\mathrm{MBA}$ at $1080 \mathrm{~cm}^{-1}$, the SERS enhancement generating from the B-GMNPs is approximated to 2.89 and 1.80 times relative to the signal from the S-GMNPs synthesized by $\times 1$ and $\times 2$ growth solution respectively (Fig. 1i). This stronger enhancement is mainly attributed to the branched $\mathrm{Au}$ shell possessing rough surface topographies with many nanoscale tips and enclosed nanogaps, i.e., hot spots, which are more conducive to generate an enhanced electromagnetic field relative to the other two products with smooth surface.

Fig. 2a shows a magnified SEM image of a representative B-GMNP, in which the particle's surface is densely planted with many finger-like branched gold nanostructures in different sizes, resulting in a very rough gold shell. Fig. $2 \mathrm{~b}$ presents a typical TEM image of the B-GMNPs and a rough surface embedded many branched nanostructures can be obviously observed according to its edge profile. Generally, Fig. $2 c$ is a selected area electron diffraction (SAED) pattern of the whole B-GMNP showing in Fig. $2 \mathrm{~b}$, and the diffraction rings illustrates that the B-GMNP is polycrystalline structure enclosed with many different facets. In contrast, by recording the SAED pattern of the branched tip marked in Fig. 2b, it is clear that the branched gold structure is highly crystallized single crystal structure which can be determined by the clear electron diffraction spots shown in the inset of Fig. 2d. The HRTEM shown in Fig. 2d also confirms the single crystal structure of the branched gold and the lattice fringes with an interplanar spacing of $0.236 \mathrm{~nm}$ can be attributed to the gold (111) plane. Fig. 2e shows the XRD patterns of $\mathrm{Fe}_{3} \mathrm{O}_{4}, \mathrm{Fe}_{3} \mathrm{O}_{4} @ \mathrm{SiO}_{2}, \mathrm{Fe}_{3} \mathrm{O}_{4} @ \mathrm{SiO}_{2} @ \mathrm{Au}$ seeds, and branched $\mathrm{Fe}_{3} \mathrm{O}_{4} @ \mathrm{SiO}_{2} @ \mathrm{Au}$, respectively. These wide angle XRD patterns show the characteristic broad diffraction peaks corresponding to the spinel $\mathrm{Fe}_{3} \mathrm{O}_{4}, \mathrm{SiO}_{2}$ and cubic phase Au. $\mathrm{Fe}_{3} \mathrm{O}_{4}$ is characterized by the six specific XRD peaks positioned at the $2 \theta$ values of $30.0^{\circ}, 35.3^{\circ}, 42.9^{\circ}, 53.5^{\circ}$, $57.0^{\circ}$ and $62.4^{\circ}$ marked by solid circles in the black curve, which correspond to the (220), (311), (400), (422), (511), and (440) lattice planes of the cubic phase of $\mathrm{Fe}_{3} \mathrm{O}_{4}$ (JCPDS card No. 01-075-0449) [44], respectively. The XRD pattern of the $\mathrm{Fe}_{3} \mathrm{O}_{4} @ \mathrm{SiO}_{2}$ (the red curve) denoted by rhombus shows a reflection characteristic of amorphous $\mathrm{SiO}_{2}$ in addition to the $\mathrm{Fe}_{3} \mathrm{O}_{4}$ reflections [45]. After the adsorption of $\mathrm{Au}$ seeds, besides the peaks of $\mathrm{Fe}_{3} \mathrm{O}_{4}$ and $\mathrm{SiO}_{2}$, four peaks of gold can be observed from the blue curve corresponding to the diffractions from the (111), (200), (220), and (311) planes of the face-centered-cubic (fcc) phase (JCPDS card
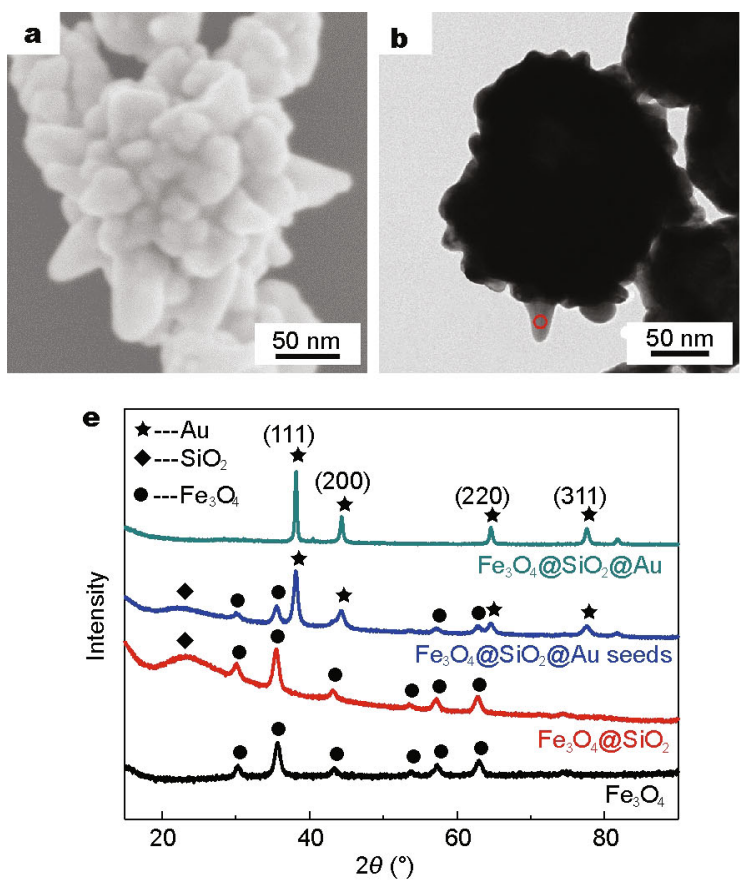
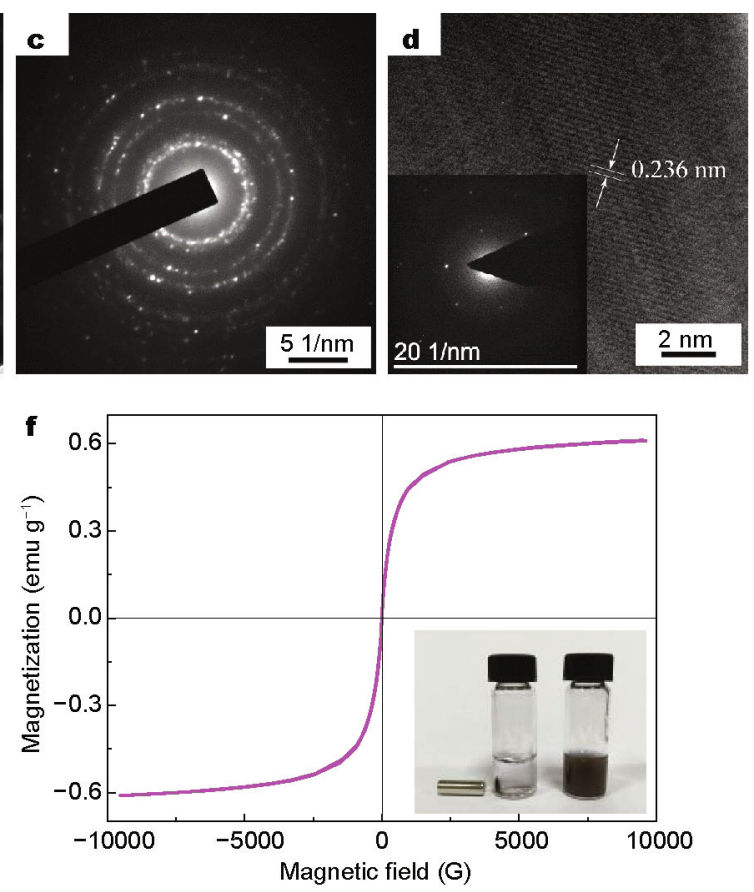

Figure 2 Detailed characterizations of the B-GMNPs. (a) SEM image of a single B-GMNP; (b) TEM image of a single B-GMNP; (c) SAED pattern of a whole B-GMNP; (d) HRTEM image obtained from the circle area marked in (b) and the corresponding SAED pattern (inset). (e) XRD patterns of Fe $\mathrm{O}_{4}$,

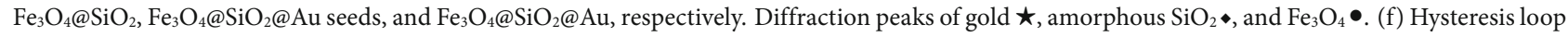
of the B-GMNPs and a photograph of the magnetic separation (inset). 
No. 00-004-0784). After growth of the Au seeds to branched Au shell, since the nanoparticles were coated by a continuous layer of $\mathrm{Au}$, only diffraction patterns of gold can be observed. It is noteworthy that the intensity of the (111) diffraction peak is much higher than the other peaks, indicating that these branched magnetic nanoparticles possess plenty of (111) facets, which is consistent with the SAED analysis and HRTEM result. The superparamagnetism of B-GMNPs was characterized by VSM and the result is shown in Fig. $2 \mathrm{f}$, in which the curve intersects with the origin point and the saturation magnetization (MS) of the B-GMNPs is found to be $0.612 \mathrm{emu}^{-1}$. In the practical separation test (inset), the B-GMNPs can be completely separated from the solution when an external magnetic field is applied.

\section{Effects of the reactant agents on the growth of B-GMNPs}

Influence of growth solution

In order to study the influence of reactant agents especially $\mathrm{HAuCl}_{4}$ and $\mathrm{AgNO}_{3}$ on the morphological, optical and SERS properties of the proposed B-GMNPs, some experiments were designed and carried out by tuning the dosage of $\mathrm{HAuCl}_{4}$ in the growth solution and the dosage of $\mathrm{AgNO}_{3}$, respectively. Fig. 3 shows the characterizations of the as-prepared GMNPs synthesized by three different dosages of growth solutions with all other parameters fixed $\left(20 \mu \mathrm{L}\right.$ of $10 \mathrm{mmolL}^{-1} \mathrm{AgNO}_{3}$ ). As the TEM and SEM images shown in Fig. 3a-f, with the increasing dosages of growth solution the morphologies of products transform from incomplete $\mathrm{Au}$ shells $(\times 1$, Fig. 3a, d) to branched
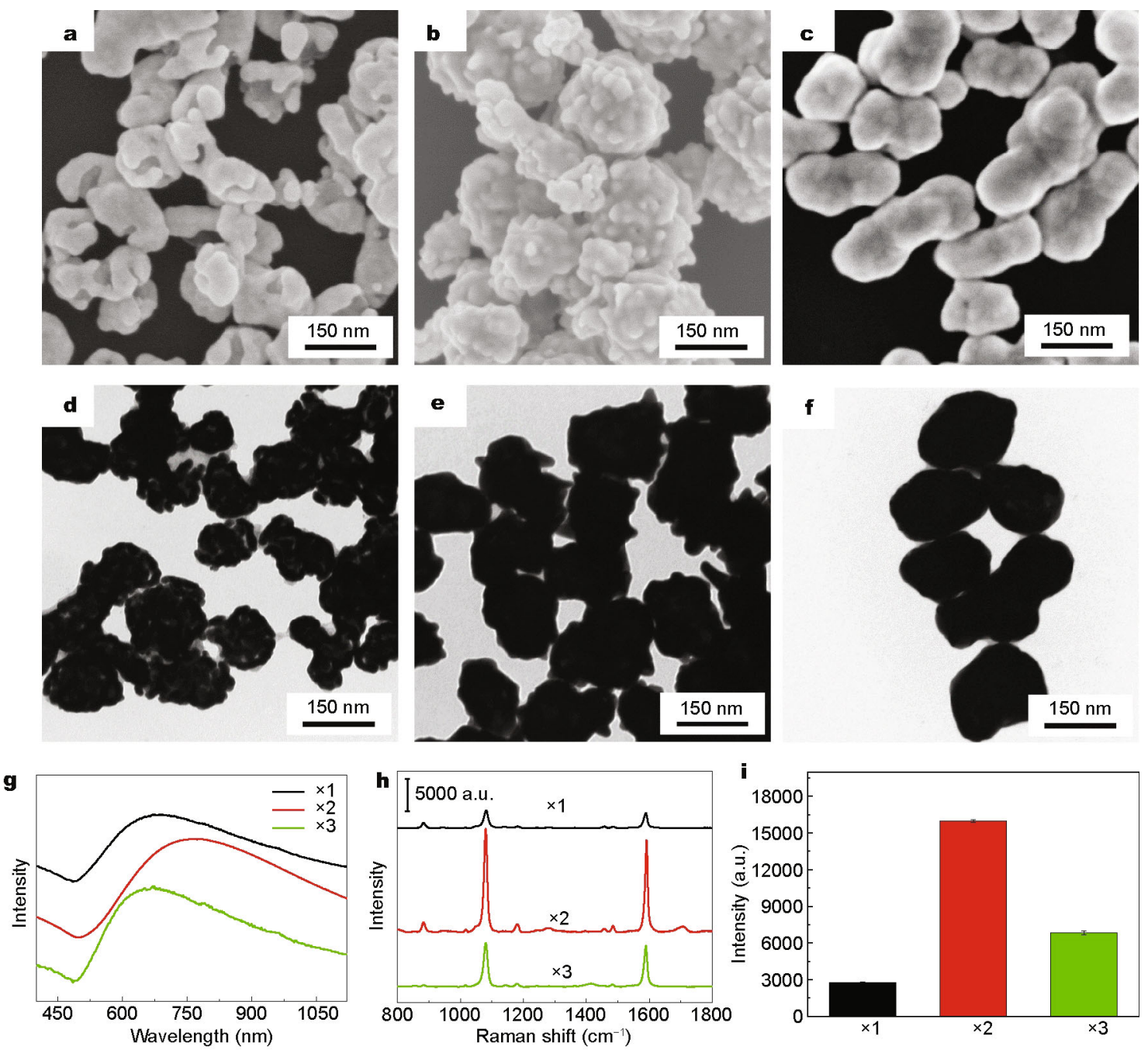

Figure 3 The GMNPs synthesized by three different dosages of growth solutions, one fold ( $\times 1)$ (a), two folds ( $\times 2)(b)$, and three folds $(\times 3)$ (c). SEM images (a-c), TEM images (d-f), absorption spectra (g), SERS spectra (h), and SERS intensity of 4-MBA (i) at $1080 \mathrm{~cm}^{-1}$ corresponding to the three kinds of GMNPs, respectively $(n=10)$. 
nanostructures $(\times 2$, Fig. $3 \mathrm{~b}, \mathrm{e})$, and then to continuously smooth shells $(\times 3$, Fig. $3 c, f)$. The absorption spectra show that the LSPR peak of the incomplete Au shells is centered at $680 \mathrm{~nm}$ (black curve in Fig. 3g). Along with the increase of growth solution, the morphology changes result in a red-shift of LSPR peak to $765 \mathrm{~nm}$ (branched nanostructure, red curve in Fig. $3 \mathrm{~g}$ ) and finally blue-shift to $651 \mathrm{~nm}$ of the continuously smooth Au shells (green curve in Fig. $3 \mathrm{~g}$ ). Thus, the surface morphology of the Au shell can be tuned by the dosage of the growth solution, and the optimum dosage of growth solution to synthesize branched Au shell is two folds dosage of growth solution. The growth solutions with less dosages of $\mathrm{HAuCl}_{4}$ and $\mathrm{K}_{2} \mathrm{CO}_{3}$ may generate GMNPs with incomplete Au shell, while once more dosages of $\mathrm{HAuCl}_{4}$ and $\mathrm{K}_{2} \mathrm{CO}_{3}$ are used, the nanoparticles tend to be coated with a layer of smooth and compact Au shells. The morphology evolutions also result in changes of SERS activities. The SERS intensity at $1080 \mathrm{~cm}^{-1}$ (Fig. 3i) detected from the branched nanostructures $(\times 2)$ is 5.79 times as much as the GMNPs with incomplete Au shells $(\times 1)$, and 2.47 times of the GMNPs with continuously smooth shells $(\times 3)$.

\section{Influence of $\mathrm{AgNO}_{3}$}

It is well known that $\mathrm{AgNO}_{3}$ can be utilized as an important morphology controlling reagent for the growth of anisotropic gold nanoparticles. Thus the dosage of silver nitrate is expected to play a key role in the synthesis of the proposed branched Au shell. Herein, $10 \mathrm{mmolL}^{-1} \mathrm{AgNO}_{3}$ solution was divided into four parts, $10,20,30$ and $50 \mu \mathrm{L}$, and utilized respectively to synthesize the nanostructures with the other parameters unchanged. As the results mentioned in Fig. 1, the Au shell appears a smooth surface in the absence of $\mathrm{AgNO}_{3}$ with the LSPR peak at $676 \mathrm{~nm}$ (red curve in Fig. 1g). Once $10 \mu \mathrm{L}$ of $10 \mathrm{mmolL}^{-1} \mathrm{AgNO}_{3}$ is used for directional growth of Au shell, several small protrusions form on the surface (Fig. 4a, b) with the overall size of $190 \pm 13 \mathrm{~nm}$ and the nanostructures generate a strong LSPR peak centered at $713 \mathrm{~nm}$ (black curve in Fig. 4i). The SERS characterization of the $10 \mu \mathrm{L} \mathrm{AgNO}_{3}$ synthesized GMNPs displays distinct characteristic peaks of $4-\mathrm{MBA}$ at 1080 and $1589 \mathrm{~cm}^{-1}$ (black curve in Fig. $4 j$ ), respectively. Fig. $4 c$ shows the morphologies of nanoparticles synthesized by $20 \mu \mathrm{L}$ of $10 \mathrm{mmolL}^{-1} \mathrm{AgNO}_{3}$. The mean diameter of nanoparticles slightly increases to $200 \pm 16 \mathrm{~nm}$, while their surfaces possess a large number of densely distributed branch-like protrusions with some branches reaching $40 \pm 3 \mathrm{~nm}$ in length. The special size contributes to the red-shift of LSPR peak to $769 \mathrm{~nm}$ (red curve in Fig. 4i). Due to the distinct nanoscale branched protrusions forming abundant "hot spots" on the rough surface of GMNPs, the SERS activity of the $20 \mu \mathrm{L} \mathrm{AgNO}_{3}$ products is 2.42 times as much as the ones prepared by $10 \mu \mathrm{L} \mathrm{AgNO}_{3}$ (red curve in Fig. 4j). Further increase of $\mathrm{AgNO}_{3}$ to $30 \mu \mathrm{L}$, both the overall sizes of nanoparticles and the length of protrusions decrease (Fig. 4e). The nanoparticles are coated with discontinuous Au shells that consist of many conjugated gold islands which grew from the previous Au seeds, and the size of nanoparticles decreases to $160 \pm 10 \mathrm{~nm}$ (Fig. 4f), resulting in a blue-shift of the LSPR peak to $688 \mathrm{~nm}$ (green curve in Fig. 4i) and an obvious decrease $(43.8 \%)$ of the corresponding SERS intensity at $1080 \mathrm{~cm}^{-1}$ compared to the signal collected from the 20 $\mu \mathrm{L} \mathrm{AgNO}{ }_{3}$ products (green curve in Fig. 4j). When $50 \mu \mathrm{L}$ $\mathrm{AgNO}_{3}$ was added, the product displays a slight change in size and the appearance of particles remains the contour of gold islands (Fig. $4 \mathrm{e}-\mathrm{h}$ ) of the $30 \mu \mathrm{L} \mathrm{AgNO}_{3}$ products. Corresponding to the imperceptible morphological changes, the LSPR peak blue-shifts slightly to $681 \mathrm{~nm}$ (blue curve in Fig. 4i), while the invisible changes are magnified by the SERS which shows $35.3 \%$ increases relative to the 30 $\mu \mathrm{L} \mathrm{AgNO}_{3}$ products but is 0.76 folds of the $20 \mu \mathrm{L} \mathrm{AgNO}_{3}$ products (blue curve in Fig. 4j). Thus the optimum dosage of $\mathrm{AgNO}_{3}, 20 \mu \mathrm{L}$, can control the directional growth of branched gold shells which possess good SERS activities.

\section{Growth kinetics of B-GMNPs}

In order to investigate the growth kinetics of the B-GMNPs, time-evolution morphological characterizations of SEM (Fig. S2), TEM and absorption spectra (Fig. 5) were performed on the nanoparticles synthesized at specific growing times, i.e., 10, 20, 30, $50 \mathrm{~min}$ and $14 \mathrm{~h}$. In this experiment, the products were washed by centrifugation so as to remove the unreacted agents and stop the growth once the synthesis reached the set growth time. After growth for $10 \mathrm{~min}$, the previous Au seeds adsorbed on the silica shell grow to big Au nanocrystals and some of them joined to form several irregular islands separated by some relatively wide "ditches" (Fig. 5a and Fig. S2a). Since the formation of islands, the size of the particles grows to $100 \pm 5 \mathrm{~nm}$, showing a weak LSPR peak centered at $616 \mathrm{~nm}$ (black curve in Fig. 5f) which red-shifts $106 \mathrm{~nm}$ relative to the previous Au seeds coated nanoparticles (Fig. S1d). In the next $10 \mathrm{~min}$, the islands grow bigger and most of the previous "ditches" are filled and the Au shells tend to become continuous films (Fig. 5b and Fig. S2b), which results in the nanoparticles growing bigger to $130 \pm 10 \mathrm{~nm}$ and making the LSPR peak red-shift to $687 \mathrm{~nm}$ (red curve in 

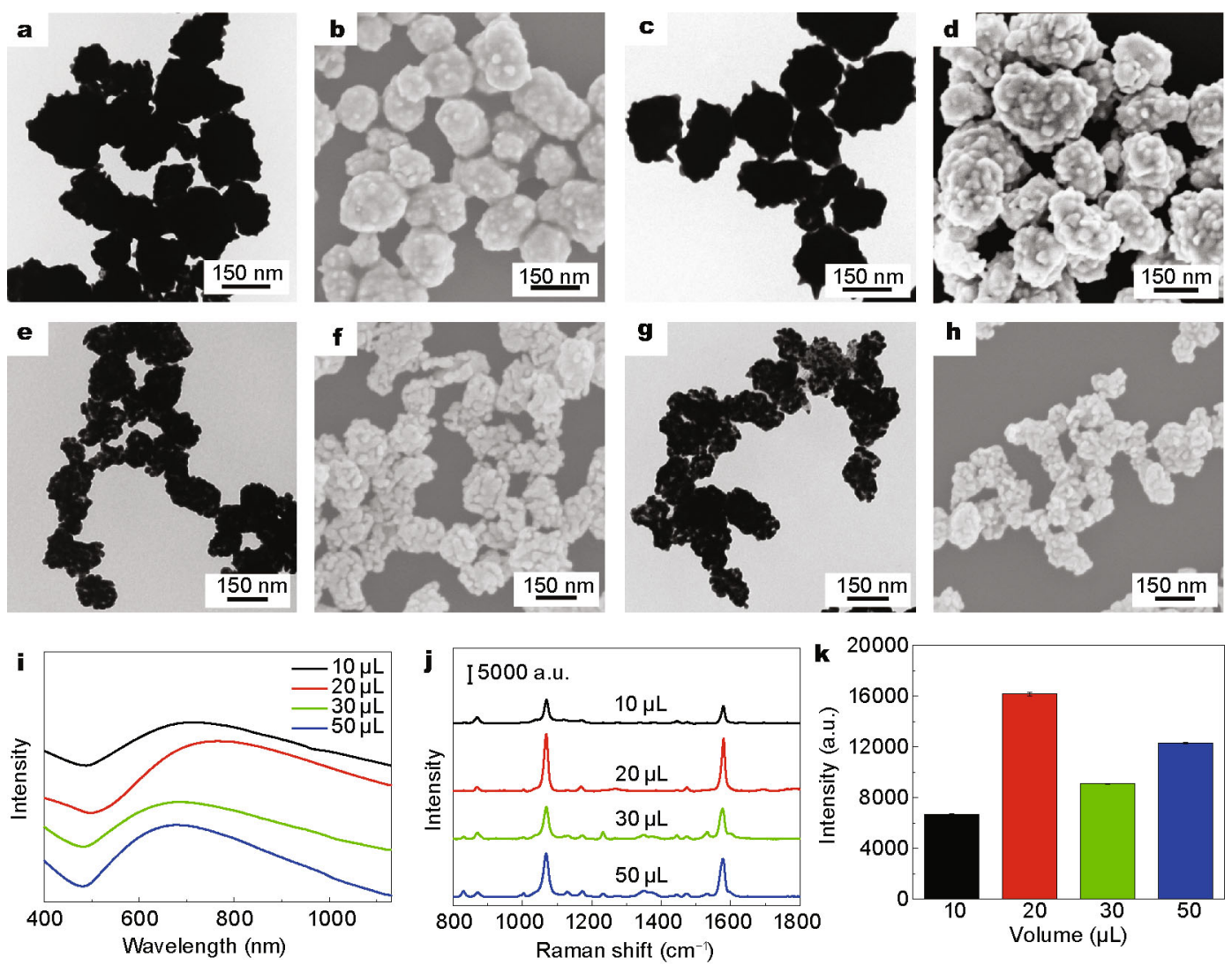

Figure 4 (a-h) TEM and SEM images of the B-GMNPs prepared by different dosages of $\mathrm{AgNO}_{3}$ solution, (a) and (b) $10 \mu \mathrm{L}$, (c) and (d) $20 \mu \mathrm{L}$, (e) and (f) $30 \mu \mathrm{L}$, (g) and (h) $50 \mu \mathrm{L}$, respectively. (i) Corresponding absorption spectra. (j) Averaged SERS spectra of 4-MBA obtained from the four products, respectively. (k) SERS intensities of $4-\mathrm{MBA}$ at $1080 \mathrm{~cm}^{-1}$ corresponding to the four SERS spectra shown in (j) $(n=10)$.

Fig. 5f). When growth for $30 \mathrm{~min}$, apparent branched shells can be clearly observed and then the whole nanoparticle grows to $200 \pm 14 \mathrm{~nm}$ (Fig. 5c and Fig. S2c). The special branched structure makes the LSPR peak red-shift to $767 \mathrm{~nm}$ (blue curve in Fig. 5f). Once growth for $50 \mathrm{~min}$, it is unexpected that the above-mentioned branched structures disappear gradually and the averaged size of nanoparticles decreases to $185 \pm 8 \mathrm{~nm}$ (Fig. $5 \mathrm{~d}$ and Fig. S2d). The morphological evolution results in a blue-shift of LSPR peak to $681 \mathrm{~nm}$ (cyan curve in Fig. 5f). After that, if the reaction continues, the surface of particles tends to coat a relatively smooth gold shell with unobvious change in size. Fig. 5e shows the nanoparticles growth for $14 \mathrm{~h}$, according to the SEM shown in Fig. S2, the particles possess smooth $\mathrm{Au}$ shells with an averaged diameter about $185 \pm 16 \mathrm{~nm}$ (Fig. 5e) and their collective LSPR peak blue-shifts to $650 \mathrm{~nm}$ (Fig. $5 \mathrm{f})$ due to the disappearance of protrusions and the decrease of particle size.

\section{Growth mechanism}

According to the investigation on growth kinetics and char- acterizations of the proposed B-GMNPs' properties, the growth mechanism can be preliminary figured out. Generally, the growth of branched Au shell is both thermodynamically and kinetically controlled process. As shown in Fig. 6 , in the early stage of the reaction, the reduced $\mathrm{Au}$ atoms are deposited onto the Au seeds via catalytic reduction of gold ions on their surface (case 1 in Fig. 6) [46]. This seedmediated growth is significant different from the typical synthesis of Au nanorods, since the proposed seeds are distributed on silica surface rather than dispersed in solution, meanwhile there is absence of "face-blocking" surfactant $\mathrm{CTAB}$ relative to $\mathrm{Au}$ nanorods synthesis. Thus, due to the sustained seed-mediated catalytic reduction and thermodynamically-controlled reaction, many large Au nanocrystals like small islands with the seeds as anchors form preferentially (case 2 in Fig. 6, and Fig. 5a) rather than growing rod-like structures. During the further process, along with the formation of islands some as-formed islands grow bigger and then some adjacent islands connect and coalesce. As a result, many long and large islands with irregular shapes generate on the surface (case 3 in Fig. 6, and 

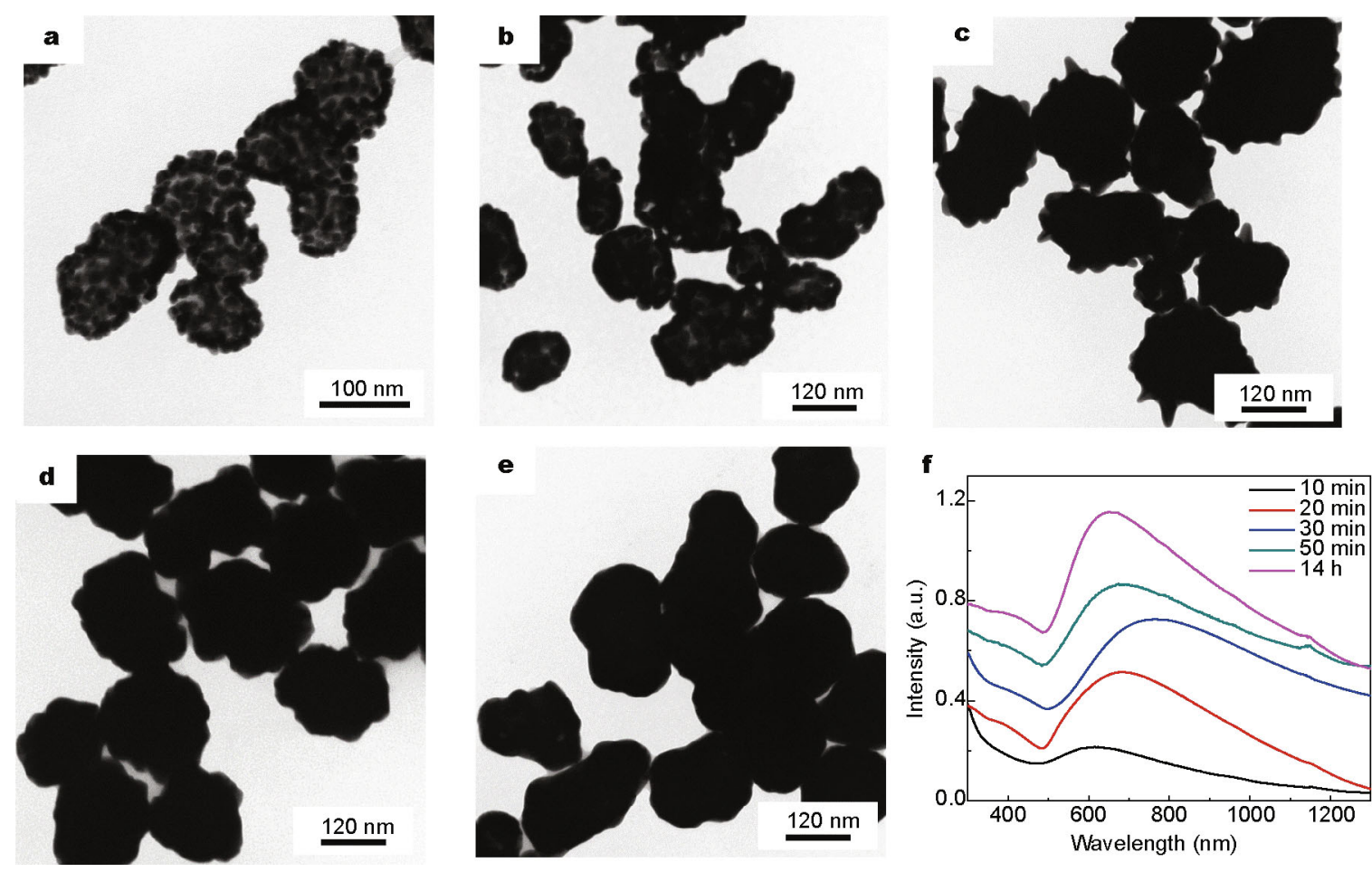

Figure 5 (a-e) Time-evolution TEM images, 10, 20, 30, $50 \mathrm{~min}$ and 14h, respectively. (f) Time-evolution absorption spectra.

Fig. 5b), which looks like mountain ranges separated by valleys. Since the continuous growth, the "valleys" are filled and a relatively continuous but rough film enclosed with different facets, such as (111), (100), (110), and (311), forms on each nanoparticle (case 4 in Fig. 6) to minimize the surface energy [47]. After that silver ion additives significantly deposit epitaxially onto the gold crystals due to the underpotential deposition (UPD), and prefer to adsorb onto sites with high coordination number relative to gold, such as protuberances and step edges [48]. Herein, since silver preferentially deposits onto (111) facet, gold depositions on (111) facets are inhibited. As a result, the growth rates of the passivated (111) facets are lower and the released $\mathrm{Au}$ atoms are directionally added to un-passivated facets. These Au atoms can be preferentially captured and then overgrow on the protuberances due to the higher tendency of the protuberant edges to capture gold atoms $[49,50]$, which can lead to a significantly anisotropic growth of branched structures (case 5 in Fig. 6, and Fig. 5c) [51]. The following disappearance of branches shown in Fig. 5d, e (corresponding to cases 6 and 7 in Fig. 6) is mainly ascribed to the excessive consumption of $\mathrm{Ag}$ ions, which results in failure UPD and facet specific passivation. Thus, the atoms deposit randomly onto the surface mainly due to the seed-mediated catalytic reduction and thermal diffusion motion. It should be noted that the possibility of the disappearance of branches due to the instability of branched structure can be eliminated. Fig. S3 characterizes the stability of the proposed B-GMNPs, in which Fig. S3a, b show the SEM images of the purified fresh B-GMNPs and the nanoparticles stored for one month. The insets show the corresponding TEM images. According to the TEM and SEM images, no significant morphological change can be observed after one month. This result is also confirmed by absorption characterizations of the fresh (black curve) and one month aged (red curve) B-GMNPs as shown in Fig. S3c, in which almost no change of the peak position can be observed. These results confirm that the as-proposed branched Au shells as well as the B-GMNPs are stable for more than one month.

\section{Characterization of DNA tetrahedrons}

The DNA tetrahedron was hierarchically assembled from three thiolated DNA fragments of 55 nucleotides (55-nt) (A, B, and C shown in Table S1 and Scheme 1b) and one capture strand containing DNA fragment (71-nt) which has a special designed oligonucleotide complementary to the target (D shown in Table S1 and Scheme 1b). The four DNA fragments were mixed in stoichiometric equivalents to assemble DNA tetrahedrons. Fig. 7a shows the electrophoresis of the formation of tetrahedral DNA. Notably, the tetrahedral DNA (lane 15) possesses a high yield of over $85 \%$ 


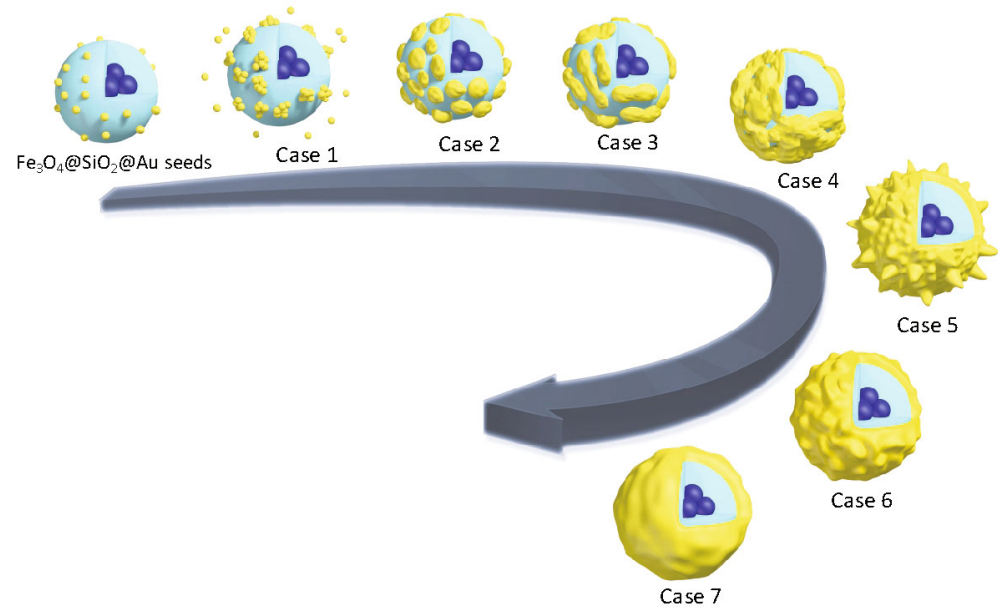

Figure 6 Scheme of the growth process of B-GMNPs.

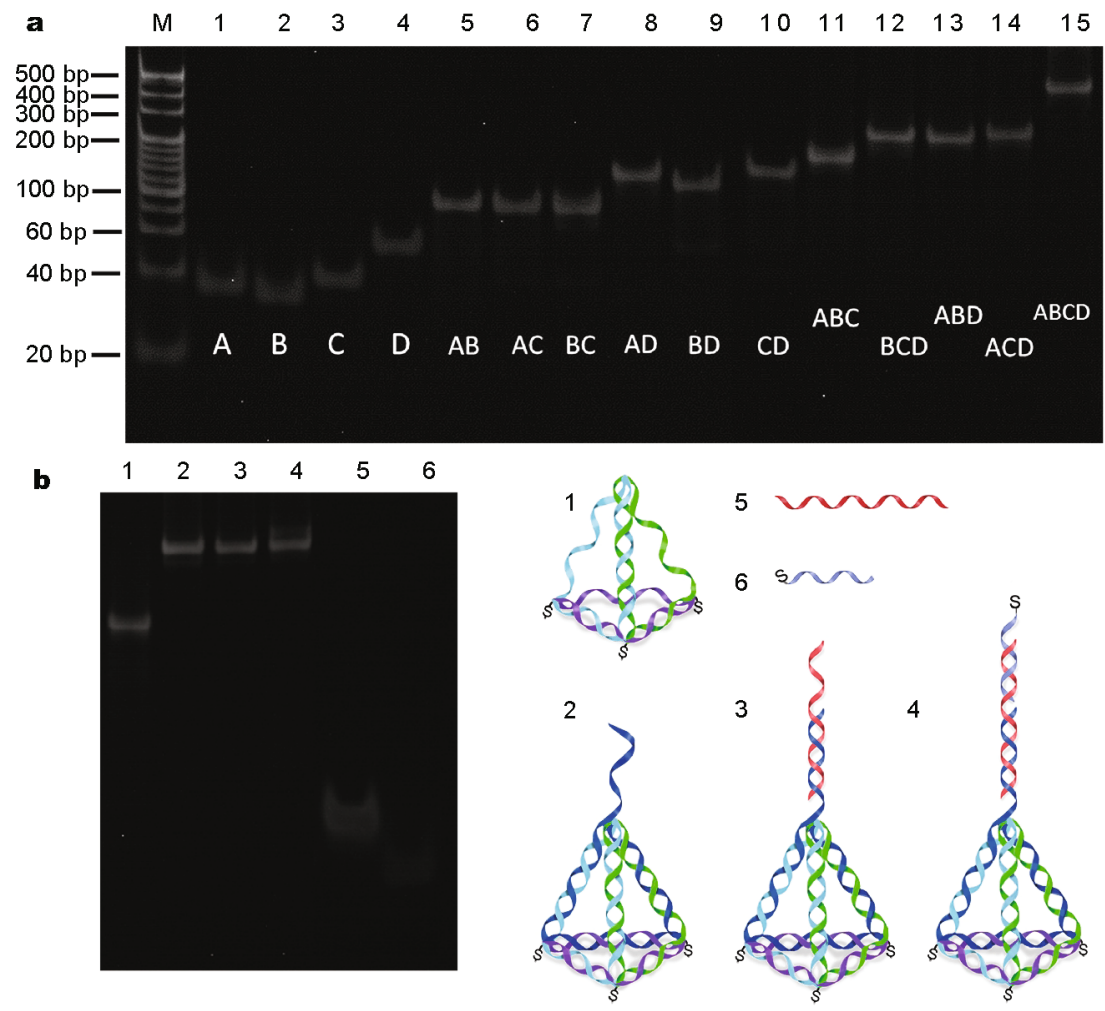

Figure 7 (a) Native PAGE (10\%) analysis of the formation of DNA tetrahedron structure. 20 bp Ladder (lane M), four ssDNAs (lane 1-4), DNA hybridizations of two ssDNAs (lane 5-10), DNA hybridizations of three ssDNAs (lane 11-14), and DNA tetrahedron (lane 15); (b) native PAGE (8\%) analysis of sandwich assay with DNA tetrahedron. Lane 1 represents ABC for a reference, lane 2 for DNA tetrahedron, lane 3 for DNA tetrahedron+target, lane 4 for DNA tetrahedron+target+probe DNA, lane 5 for target, lane 6 for probe DNA.

according to the one major band resolved during electrophoresis [37], which also suggests that the additional sequences and thiol groups did not significantly interfere with the assembly. Control studies show that the DNA tetrahedron moves more slowly than either the ssDNAs or other combinations which are lack of one or two strands.
These results confirm the successful assembly of the tetrahedron nanostructure. The native PAGE analysis shown in Fig. 7b verifies the effective hybridization of the target and probe DNA with DNA tetrahedron. The DNA tetrahedron, target and probe DNA were mixed in stoichiometric equivalents in TM buffer. Observing 
lane 3 (tetrahedron+target), one can see that the DNA tetrahedrons-target band migrated slight slower than DNA tetrahedrons (lane 2), without any new band in the corresponding position of target (land 5), which suggests that the target was bound with the DNA tetrahedrons. Similarly, lane 4 (tetrahedron+target+probe DNA) also moved slower than lane 3 (tetrahedron+target) and did not see any new band of target or probe DNA (lane 6), even the complex of target and probe DNA, which suggests that the designed DNA tetrahedron can successfully capture the target and further hybridize with the probe DNA.

\section{Characterizations of SERS tags}

The formation of SERS tags was monitored by absorption spectra. Fig. S4a shows the absorption spectra of AuNPs after surface modification of probe DNA and further linking with DTNB, respectively. The absorption peak of the AuNPs is centered at $519 \mathrm{~nm}$, and then red-shifts 4 to $523 \mathrm{~nm}$ after modification of SH-DNA via S-metal covalent bond. In the next step, Raman reporter DTNB occupied the rest regions on the surface of AuNPs, making the LSPR peak red-shift to $524.5 \mathrm{~nm}$. The SERS response of the tags was characterized by dropping $20 \mu \mathrm{L}$ SERS tags into micropores on a silicon wafer and performing SERS scans (177.2 $\mathrm{mW}$ laser power, $5 \mathrm{~s}$ acquisition time) when the samples were dry. The SERS tags present strong DTNB Raman signal (Fig. S4b) with three apparent Raman peaks at 1060,1331 and $1556 \mathrm{~cm}^{-1}$, which belong to the succinimidyl $\mathrm{N}-\mathrm{C}-\mathrm{O}$ stretch overlapping with aromatic ring modes, the symmetric nitro stretching vibration, and the aromatic ring vibration of DTNB $[52,53]$, respectively. The SERS result indicates that the bright SERS tags have good performance on SERS signal output. The signal stability of the SERS tags was also investigated by storing the SERS tags in PBS at room temperature and recording their SERS spectra for over two weeks. Fig. S5a shows the time-dependent SERS spectra collected every other day, from fresh to $16 \mathrm{~d}$. Fig. S5b plots the intensity at $1331 \mathrm{~cm}^{-1}$ as a relationship of storage day, which shows a very small relative standard deviation (RSD) within $1.90 \%$. The result reveals that the SERS tags possess a stable output of SERS signals even after two weeks' storage.

\section{Characterizations of the tetrahedral DNA modified B-GMNPs}

Tetrahedral DNAs self-assembled onto Au shells by their thiol groups, and the surface modifications of B-GMNPs were monitored by zeta-potential characterizations and the data were shown in Table S2. The zeta-potential value of B-GMNPs is $-23.01 \pm 0.27 \mathrm{mV}$ and then changes to $-30.65 \pm 0.64 \mathrm{mV}$ after surface modification with DNA tetrahedron due to a large number of negatively charged DNA molecules coating on the their surface, which indicates that the DNA tetrahedrons anchored on the Au shell successfully. In addition, given that the tetrahedral DNA contains three thiol groups on three vertices at the base, this $3 \mathrm{D}$ nanostructure is expected to be more readily and strongly anchored on Au surfaces of the B-GMNPs.

\section{SERS assays of miRNA-21}

Fig. 8a shows the SERS assay of the miRNA-21 with different concentrations in $80 \%$ human serum $\left(C_{\text {miRNA-21 }}, 1\right.$ fmol L ${ }^{-1}, 10 \mathrm{fmol} \mathrm{L}^{-1}, 100 \mathrm{fmol} \mathrm{L}^{-1}, 1 \mathrm{pmol} \mathrm{L}{ }^{-1}, 10 \mathrm{pmol} \mathrm{L}^{-1}$ and $100 \mathrm{pmol} \mathrm{L}^{-1}$ ), respectively, and a blank control was also detected by performing the assay without adding any miRNAs but human serum (black curve in Fig. 8a). The SERS spectra indicate that the miRNA-21 can be monitored by the $1331 \mathrm{~cm}^{-1}$ SERS signal of SERS tags, and trace miRNA-21 as low as $1 \mathrm{fmol} \mathrm{L}^{-1}$ could still be distinguished from the blank control. According to the concentration dependent SERS spectra, a good linear equation, $I=413.1 \times \log$ $C_{\text {miRNA-21 }}+6745.0$ with a correlation coefficient $\left(R^{2}\right)$ of 0.998 , is obtained between the peak intensity and the logarithm of miRNA-21 concentration from $1 \mathrm{fmol} \mathrm{L}^{-1}$ to $100 \mathrm{pmol}$ $\mathrm{L}^{-1}$ as shown in Fig. 8b. Defining the lowest concentration that produces a signal three times stronger than the standard deviation of the blank control $[54,55]$, the limit of detection (LOD) is calculated to be $623 \mathrm{amol} \mathrm{L}{ }^{-1}$. The specificity of the assay was further investigated by replacing miRNA-21 ( $\left.1 \mathrm{nmol} \mathrm{L}^{-1}\right)$ with equivalent amount of noncomplementary miRNAs (miRNA-486) and single-base mismatch miRNAs (listed in Table S1) respectively following the same sensing protocol. As shown in Fig. $8 \mathrm{c}$, the characteristic peak at $1331 \mathrm{~cm}^{-1}$ is difficult to be observed from the corresponding SERS spectra of noncomplementary (blue curve) and single-base mismatch (purple curve) detections with respect to the obvious SERS signal of complementary assay (red curve). The mixture containing three miRNAs miRNA-21/486/375 with the same concentration $\left(1 \mathrm{nmol} \mathrm{L}{ }^{-1}\right)$ was also conducted, and the result indicates that miRNA-21 still could be readily distinguished from the SERS spectrum (orange curve). These experimental results demonstrate that the proposed method can sensitively and specifically recognize the target miRNAs in the complicated human serum with complex mixtures with negligible cross-impact, which indicates the proposed B-GMNPs integrating superparamagnetism with improved SERS activity can be used as good SERS 

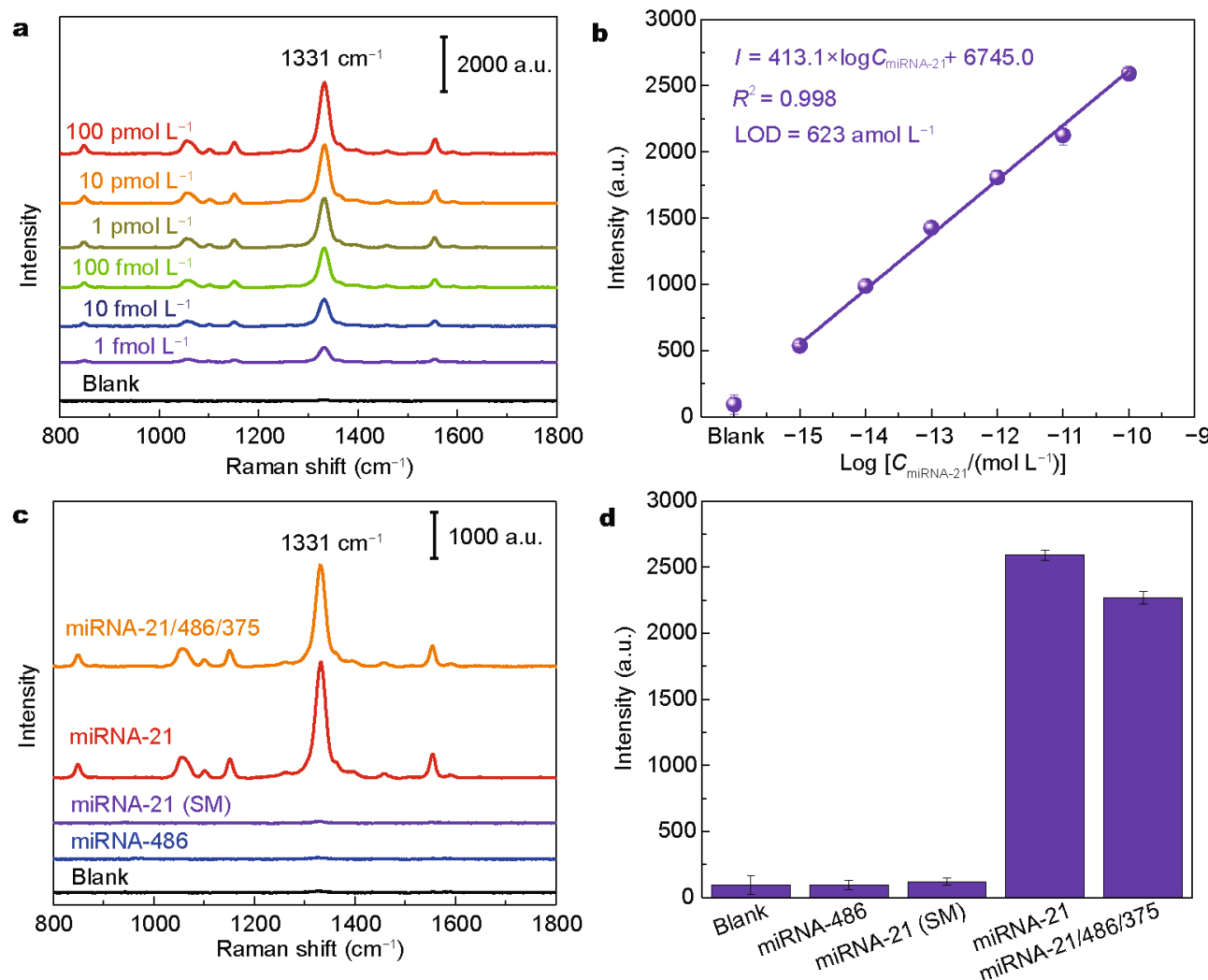

Figure 8 SERS assays for miRNA-21 in human serum. (a) Concentration-dependent SERS spectra; (b) linear fitting of the peak intensity at $1331 \mathrm{~cm}^{-1}$ as a function of concentration of miRNA-21; (c) specificity assessment: SERS spectra obtained from blank, noncomplementary miRNA-486, single-base mismatched miRNA, miRNA-21 and the mixture of three miRNA-21/375/486 $\left(1 \mathrm{nmol} \mathrm{L}^{-1}\right)$; $(\mathrm{d})$ corresponding peak intensities at $1331 \mathrm{~cm}^{-1}(n=10)$.

substrates for biological detection with the functions of external magnetic field controlled sample separation and directional enrichment. What's more, the good sensitivity and specificity also take advantages of the DNA tetrahedrons, i.e., they are well-defined and rigid structures with consistently favorable orientation and well-defined spacing on the gold surface, inherently insensitive to nuclease degradation and resistive to protein adsorption in serum, compared to previously reported linear or stem-loop DNA structures.

As a control, the same sensing protocol for detecting miRNA-21 (1 pmol L ${ }^{-1}$ ) was performed by using S-GMNPs. According to the two spectra shown in Fig. S6a and the corresponding peak intensities at $1331 \mathrm{~cm}^{-1}$ shown in Fig. S6b, the SERS signal obtained from B-GMNPs sensing system is approximately 5.82 times as strong as that from S-GMNPs sensing system. The result reveals that an improved detection sensitivity can be achieved by utilizing the novel B-GMNPs, which is mainly attributed to three factors. Firstly, B-GMNPs have more "hot spots" with improved SERS activity. Secondly, in the sandwich-structured composites forming after hybridization, the branch-like protrusions on the B-GMNPs can couple with AuNPs SERS tags to generate enhanced SERS effect. Thirdly, B-GMNPs with rough surface topographies possess larger surface area for assembling more tetrahedral DNAs so as to enhance the ability to capture SERS tags.

\section{CONCLUSIONS}

In this work, a novel type of branched gold coated magnetic nanoparticles (B-GMNPs), $\mathrm{Fe}_{3} \mathrm{O}_{4} @ \mathrm{SiO}_{2} @ \mathrm{Au}$, has been prepared by a seed-mediated method together with the shape induction agent $\mathrm{AgNO}_{3}$. The growth process and mechanism, properties, as well as morphologically controlled synthesis of the magnetic core-branched gold shell nanostructures were also investigated by absorption spectra, TEM, HRTEM, SEM, SAED, XRD, VSM, and especially SERS. The B-GMNPs show enhanced SERS enhancement effect since there are many branched gold tips distributed on their surfaces. The B-GMNPs with improved SERS activity were further utilized to build SERS-active and magnetic detection capturers for sandwich-structured detection of cancer-related biomarker miRNA-21. In this step sulfhydryl groups decorated tetrahedral DNA cap- 
turers were structured first by assembling four specially designed single stranded DNAs and then assembled onto the B-GMNPs via S-metal bonds. After incubation the SERS-active and magnetic capturers with serum samples and SERS tags, sandwich-structured composites of hybridization were magnetically purified and concentrated for SERS measurements. The SERS results illustrate that highly sensitive and specific detections of cancer-related biomarker can be obtained by a sandwich-structured sensing strategy by using tetrahedral DNA modified B-GMNPs as SERS-active capturers, magnetic separation and enrichment operators, and the LOD of the miRNA-21 in serum is $623 \mathrm{amol} \mathrm{L} \mathrm{L}^{-1}$. These experimental results indicates that the proposed B-GMNPs integrating superparamagnetism with improved SERS activity can be used as good SERS substrates with the functions of external magnetic field controlled sample separation and directional enrichment, which is highly advantageous to SERS-based biochemical sensing and detections.

\section{Received 31 January 2017; accepted 27 March 2017;} published online 9 May 2017

1 Yang D, Ma J, Zhang Q, et al. Polyelectrolyte-coated gold magnetic nanoparticles for immunoassay development: toward point of care diagnostics for syphilis screening. Anal Chem, 2013, 85: 6688-6695

2 Zheng J, Dong Y, Wang W, et al. In situ loading of gold nanoparticles on $\mathrm{Fe}_{3} \mathrm{O}_{4} @ \mathrm{SiO}_{2}$ magnetic nanocomposites and their high catalytic activity. Nanoscale, 2013, 5: 4894-4901

3 Lu AH, Salabas EL, Schüth F. Magnetic nanoparticles: synthesis, protection, functionalization, and application. Angew Chem Int Ed, 2007, 46: 1222-1244

4 Espinosa A, Di Corato R, Kolosnjaj-Tabi J, et al. Duality of iron oxide nanoparticles in cancer therapy: amplification of heating efficiency by magnetic hyperthermia and photothermal bimodal treatment. ACS Nano, 2016, 10: 2436-2446

5 Tintoré M, Mazzini S, Polito L, et al. Gold-coated superparamagnetic nanoparticles for single methyl discrimination in DNA aptamers. IJMS, 2015, 16: 27625-27639

6 Chuah K, Lai LMH, Goon IY, et al. Ultrasensitive electrochemical detection of prostate-specific antigen (PSA) using gold-coated magnetic nanoparticles as "dispersible electrodes". Chem Commun, 2012, 48: 3503-3505

7 Qi D, Zhang H, Tang J, et al. Facile synthesis of mercaptophenylboronic acid-functionalized core-shell structure $\mathrm{Fe}_{3} \mathrm{O}_{4} @ \mathrm{C} @ \mathrm{Au}$ magnetic microspheres for selective enrichment of glycopeptides and glycoproteins. J Phys Chem C, 2010, 114: 9221-9226

8 Guven B, Basaran-Akgul N, Temur E, et al. SERS-based sandwich immunoassay using antibody coated magnetic nanoparticles for Escherichia coli enumeration. Analyst, 2011, 136: 740-748

9 Sun $\mathrm{M}, \mathrm{Xu} \mathrm{L}, \mathrm{Ma} \mathrm{W}$, et al. Hierarchical plasmonic nanorods and upconversion core-satellite nanoassemblies for multimodal imaging-guided combination phototherapy. Adv Mater, 2016, 28 : 898-904

10 Wang Y, Yan B, Chen L. SERS tags: novel optical nanoprobes for bioanalysis. Chem Rev, 2013, 113: 1391-1428
11 Wang Y, Chen L, Liu P. Biocompatible triplex Ag@SiO $@_{2} \mathrm{mTiO}_{2}$ core-shell nanoparticles for simultaneous fluorescence-SERS bimodal imaging and drug delivery. Chem Eur J, 2012, 18: 5935-5943

12 Wang M, Meng G, Huang Q, et al. CNTs-anchored egg shel membrane decorated with Ag-NPs as cheap but effective SERS substrates. Sci China Mater, 2015, 58: 198-203

13 Duan C, Ren B, Liu H, et al. Flexible SERS active detection from novel Ag nano-necklaces as highly reproducible and ultrasensitive tips. Sci China Mater, 2016, 59: 435-443

14 Zhen S, Wu T, Huang X, et al. Facile synthesis of gold nanoflowers as SERS substrates and their morphological transformation induced by iodide ions. Sci China Chem, 2016, 59: 1045-1050

15 Song C, Yang B, Yang Y, et al. SERS-based mercury ion detections: principles, strategies and recent advances. Sci China Chem, 2016, 59: $16-29$

$16 \mathrm{Xu} \mathrm{Z}$, Hou Y, Sun S. Magnetic core/shell $\mathrm{Fe}_{3} \mathrm{O}_{4} / \mathrm{Au}$ and $\mathrm{Fe}_{3} \mathrm{O}_{4} / \mathrm{Au} / \mathrm{Ag}$ nanoparticles with tunable plasmonic properties. J Am Chem Soc, 2007, 129: 8698-8699

17 Kouassi GK, Irudayaraj J. Magnetic and gold-coated magnetic nanoparticles as a DNA sensor. Anal Chem, 2006, 78: 3234-3241

18 Cho SJ, Shahin AM, Long GJ, et al. Magnetic and Mössbauer spectral study of core/shell structured Fe/Au nanoparticles. Chem Mater, 2006, 18: 960-967

19 Jin Y, Jia C, Huang SW, et al. Multifunctional nanoparticles as coupled contrast agents. Nat Commun, 2010, 1: 41-48

$20 \mathrm{Hu}$ Y, Meng L, Niu L, et al. Facile synthesis of superparamagnetic $\mathrm{Fe}_{3} \mathrm{O}_{4} @$ polyphosphazene@Au shells for magnetic resonance imaging and photothermal therapy. ACS Appl Mater Interfaces, 2013, 5: 4586-4591

21 Goon IY, Lai LMH, Lim M, et al. Fabrication and dispersion of gold-shell-protected magnetite nanoparticles: systematic control using polyethyleneimine. Chem Mater, 2009, 21: 673-681

22 Song C, Min L, Zhou N, et al. Ultrasensitive detection of carcino-embryonic antigen by using novel flower-like gold nanoparticle SERS tags and SERS-active magnetic nanoparticles. RSC Adv, 2014, 4: 41666-41669

23 Moraes Silva S, Tavallaie R, Sandiford L, et al. Gold coated magnetic nanoparticles: from preparation to surface modification for analytical and biomedical applications. Chem Commun, 2016, 52: 7528-7540

24 Li F, Yu Z, Zhao L, et al. Synthesis and application of homogeneous $\mathrm{Fe}_{3} \mathrm{O}_{4}$ core/Au shell nanoparticles with strong SERS effect. RSC Adv, 2016, 6: 10352-10357

25 Tang X, Dong R, Yang L, et al. Fabrication of Au nanorod-coated $\mathrm{Fe}_{3} \mathrm{O}_{4}$ microspheres as SERS substrate for pesticide analysis by near-infrared excitation. J Raman Spectrosc, 2015, 46: 470-475

26 Chen J, Pang S, He L, et al. Highly sensitive and selective detection of nitrite ions using $\mathrm{Fe}_{3} \mathrm{O}_{4} @ \mathrm{SiO}_{2} / \mathrm{Au}$ magnetic nanoparticles by surface-enhanced Raman spectroscopy. Biosens Bioelectron, 2016, 85: 726-733

27 Mo AH, Landon PB, Gomez KS, et al. Magnetically-responsive silica-gold nanobowls for targeted delivery and SERS-based sensing. Nanoscale, 2016, 8: 11840-11850

28 Zhang H, Harpster MH, Wilson WC, et al. Surface-enhanced Raman scattering detection of DNAs derived from virus genomes using Au-coated paramagnetic nanoparticles. Langmuir, 2012, 28: 4030-4037

29 Sharma B, Frontiera RR, Henry AI, et al. SERS: materials, applications, and the future. Mater Today, 2012, 15: 16-25

30 Song CY, Zhou N, Yang BY, et al. Facile synthesis of hydrangea flower-like hierarchical gold nanostructures with tunable surface 
topographies for single-particle surface-enhanced Raman scattering. Nanoscale, 2015, 7: 17004-17011

31 Song CY, Yang BY, Chen WQ, et al. Gold nanoflowers with tunable sheet-like petals: facile synthesis, SERS performances and cell imaging. J Mater Chem B, 2016, 4: 7112-7118

32 Hu J, Zhang Y, Liu B, et al. Synthesis and properties of tadpoleshaped gold nanoparticles. J Am Chem Soc, 2004, 126: 9470-9471

33 Rodríguez-Lorenzo L, Álvarez-Puebla RA, de Abajo FJG, et al. Surface enhanced Raman scattering using star-shaped gold colloidal nanoparticles. J Phys Chem C, 2010, 114: 7336-7340

34 Bakr OM, Wunsch BH, Stellacci F. High-yield synthesis of multibranched urchin-like gold nanoparticles. Chem Mater, 2006, 18: 3297-3301

35 Mitchell N, Schlapak R, Kastner M, et al. A DNA nanostructure for the functional assembly of chemical groups with tunable stoichiometry and defined nanoscale geometry. Angew Chem Int Ed, 2009, 48: 525-527

36 Li Z, Zhao B, Wang D, et al. DNA nanostructure-based universal microarray platform for high-efficiency multiplex bioanalysis in biofluids. ACS Appl Mater Interfaces, 2014, 6: 17944-17953

37 Pei H, Lu N, Wen Y, et al. A DNA nanostructure-based biomolecular probe carrier platform for electrochemical biosensing. Adv Mater, 2010, 22: 4754-4758

38 Pei H, Liang L, Yao G, et al. Reconfigurable three-dimensional DNA nanostructures for the construction of intracellular logic sensors. Angew Chem, 2012, 124: 9154-9158

39 Wang S, Zhang L, Wan S, et al. Aptasensor with expanded nucleotide using DNA nanotetrahedra for electrochemical detection of cancerous exosomes. ACS Nano, 2017, 11: 3943-3949

40 Wen Y, Pei H, Shen Y, et al. DNA nanostructure-based interfacial engineering for PCR-free ultrasensitive electrochemical analysis of microRNA. Sci Rep, 2012, 2: 867

41 Chen X, Zhou G, Song P, et al. Ultrasensitive electrochemical detection of prostate-specific antigen by using antibodies anchored on a DNA nanostructural scaffold. Anal Chem, 2014, 86: $7337-7342$

42 Song C, Min L, Zhou N, et al. Synthesis of novel gold mesoflowers as SERS tags for immunoassay with improved sensitivity. ACS Appl Mater Interfaces, 2014, 6: 21842-21850

43 Michota A, Bukowska J. Surface-enhanced Raman scattering (SERS) of 4-mercaptobenzoic acid on silver and gold substrates. J Raman Spectrosc, 2003, 34: 21-25

44 Zhang X, Zhu Y, Yang X, et al. Multifunctional $\mathrm{Fe}_{3} \mathrm{O}_{4} @ \mathrm{TiO}_{2} @ \mathrm{Au}$ magnetic microspheres as recyclable substrates for surface-enhanced Raman scattering. Nanoscale, 2014, 6: 5971-5979

45 Shao M, Ning F, Zhao J, et al. Preparation of $\mathrm{Fe}_{3} \mathrm{O}_{4} @ \mathrm{SiO}_{2} @$ layered double hydroxide core-shell microspheres for magnetic separation of proteins. J Am Chem Soc, 2012, 134: 1071-1077

46 Jana NR, Gearheart L, Murphy CJ. Evidence for seed-mediated nucleation in the chemical reduction of gold salts to gold nanoparticles. Chem Mater, 2001, 13: 2313-2322
47 Hong JW, Lee SU, Lee YW, et al. Hexoctahedral Au nanocrystals with high-index facets and their optical and surface-enhanced Raman scattering properties. J Am Chem Soc, 2012, 134: 4565-4568

48 Personick ML, Langille MR, Zhang J, et al. Shape control of gold nanoparticles by silver underpotential deposition. Nano Lett, 2011, 11: 3394-3398

49 You H, Ji Y, Wang L, et al. Interface synthesis of gold mesocrystals with highly roughened surfaces for surface-enhanced Raman spectroscopy. J Mater Chem, 2012, 22: 1998-2006

50 You H, Ding C, Song X, et al. In situ studies of different growth modes of silver crystals induced by the concentration field in an aqueous solution. Cryst Eng Comm, 2011, 13: 4491-4495

51 Nikoobakht B, El-Sayed MA. Preparation and growth mechanism of gold nanorods (NRs) using seed-mediated growth method. Chem Mater, 2003, 15: 1957-1962

52 Grubisha DS, Lipert RJ, Park HY, et al. Femtomolar detection of prostate-specific antigen: an immunoassay based on surface-enhanced Raman scattering and immunogold labels. Anal Chem, 2003, 75: 5936-5943

53 Shrestha YK, Yan F. Determination of critical micelle concentration of cationic surfactants by surface-enhanced Raman scattering. RSC Adv, 2014, 4: 37274-37277

54 Wang Z, Zong S, Li W, et al. SERS-fluorescence joint spectral encoding using organic-metal-QD hybrid nanoparticles with a huge encoding capacity for high-throughput biodetection: putting theory into practice. J Am Chem Soc, 2012, 134: 2993-3000

55 Wang G, Lipert RJ, Jain M, et al. Detection of the potential pancreatic cancer marker MUC4 in serum using surface-enhanced Raman scattering. Anal Chem, 2011, 83: 2554-2561

Acknowledgments This work was supported by the National Natural Science Foundation of China (21475064), Sci-tech Support Plan of Jiangsu Province (BE2014719), Program for Changjiang Scholars and Innovative Research Team in University (IRT_15R37), the Research Innovation Program for College Graduates of Jiangsu Province (SJZZ15_0107), the Scientific Research Foundation of Nanjing University of Posts and Telecommunications (NY215075), and the Priority Academic Program Development of Jiangsu Higher Education Institutions (YX03001).

Author contributions Song C, Yang Y and Wang L proposed and designed the project. Yang Y, Liu B, Chao J, Zhu D participated in the design and characterization of DNA structures. Jiang X, Zhang Q and Chen Y performed the experiments. Sun Y and Yang B characterized the materials. All the authors contributed to the writing and general discussion of the paper.

Conflict of interest The authors declare that they have no conflicts of interest.

Supplementary information Supporting data are available in the online version of the paper. 

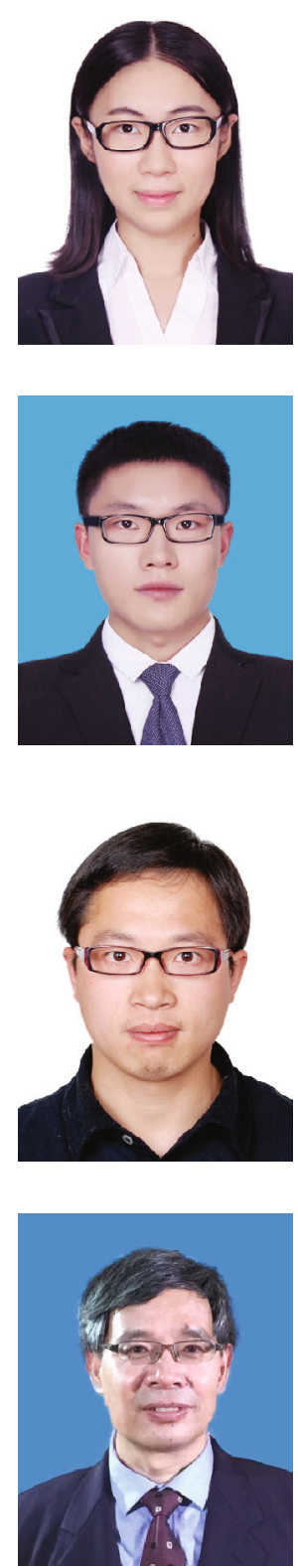

Yanjun Yang is a graduate student at the Institute of Advanced Materials, Nanjing University of Posts and Telecommunications (NJUPT) under the supervision of Prof. Lianhui Wang and Prof. Chunyuan Song. She received her Bachelor's degree from NJUPT in 2014. Her current research focuses on the development of ultrasensitive SERS sensors for multiple biochemical sensing and detections.
Xinyu Jiang is an undergraduate student at NJUPT. Currently, he is working on the Research Innovation Program for College Undergraduates of NJUPT in Prof. Wang's lab.
Chunyuan Song received his PhD degree in optical engineering from Southeast University in 2012. He is now an associate professor at the Institute of Advanced Materials, NJUPT. His research interest focuses on the synthesis, characterization and application of plasmonic nanomaterials for surface-enhanced Raman scattering based biosensing and imaging.

\section{磁核枝权状金売纳米颗粒的制备及其在肿瘤核酸标志物SERS检测中的应用研究}

杨琰君 ${ }^{\dagger}$ 蒋新宇 ${ }^{\dagger}$ 昆洁, 宋春元*, 刘冰, 朱丹, 孙友志, 杨博玥, 张乔伟, 陈叶, 汪联辉 ${ }^{*}$

摘要 复合SERS活性和超顺磁性的磁核金壳纳米颗粒在SERS传感、样品分离与富集、定向输运等方面已有广泛应用. 已报道的基于磁核 制备的金纳米壳大多为平滑的金壳, 基于磁核生长枝权状金壳可以提升颗粒的SERS增强性能,但相关报道甚少. 本文基于种子生长法并引 入定向生长控制剂 $\mathrm{AgNO}_{3}$, 合成了一种新型的磁核枝权状金壳纳米颗粒, 系统地研究了金壳的生长过程与机制、表面形貌的控制生长以及 对SERS性能的影响. 此外, 设计并构建了具有良好的结构刚性、稳定性和空间定位能力的四面体DNA 探针, 并将其修饰到磁核枝权状金壳 纳米颗粒表面构建得到检测基底. 通过在金纳米颗粒表面修饰单链DNA构建SERS探针,利用碱基互补配对形成“检测基底-目标核酸-SERS 探针”三明治结构复合物, 借助外加磁场分离检测液中的复合物并富集后进行SERS检测, 实现了对于血清中肿瘤核酸标志物 miRNA-21的 高灵敏、特异性检测, 检测限达到 $623 \mathrm{amol} \mathrm{L}{ }^{-1}$. 